Derecho \& Realidad

Vol. 13 - Núm. 25 •Enero-Junio de 2015

Pá8s. 43-62 • ISSN: 1692-3936

\title{
Regulación económica: una aproximación al marco teórico y conceptual*
}

\author{
Economic regulation: an approach to \\ theoretical and conceptual framework
}

\author{
Luz Marina Romero Alvarado** \\ maroal.33@hotmail.com
}

\section{Resumen}

El artículo presenta los principales presupuestos de partida y enfoques de la regulación: el interés general y el interés privado. El primero, que siguió los fundamentos de la teoría keynesiana del bienestar, tuvo su origen en la intervención del Estado en la economía hacia los años treinta del siglo XX, mediante la regulación, debido a la necesidad de corregir los fallos del mercado que generaban los postulados neoclásicos. El segundo surge hacia los años setenta del siglo XX, ante la fuerte crítica y controversia al modelo regulativo, por causa de los fallos del gobierno al ejercer la regulación sumado a los fallos del mercado.

Fecha de aceptación: 07 de julio de 2014

Fecha de recepción: 09 de agosto de 2014

Fecha de aprobación final: 25 de febrero de 2015

* Artículo de reflexión, producto de investigación terminada Regulación del Precio del Etanol en Colombia. ¿Teoría del Interés General o Teoría del Interés privado?

** Docente Universidad Pedagógica y Tecnológica de Colombia. 


\title{
Palabras clave
}

Regulación, mercado, gobierno, Estado y mercado, bienes públicos.

\begin{abstract}
The article presents the main postulates and approaches of the regulation: the public interest and the private interest. The first, that followed the foundations of Keynesian welfare theory, had its origin in the state intervention in the economy towards the thirties of the 20th century, through the regulation to correct market failures generated by neoclassical assumptions. The second arises towards the seventies of the same century, faced strong criticism and controversy to the traditional regulatory model, due to the failures of the government to practice regulation in addition to the market failures.
\end{abstract}

\section{Keywords}

Regulation, market, government, state and market, public goods. 


\section{Introducción}

La intervención del Estado en la economía en los primeros años de la tercera década del siglo XX, se justificó por la necesidad de corregir los fallos o imperfecciones del mercado ${ }^{1}$, generados por los postulados de la competencia perfecta. En esa época se padecían los desequilibrios típicos de dichos fallos, con sus respectivas consecuencias, que se manifestaron en crisis económicas sin precedentes. Para corregir dichos fallos, el Estado tuvo que intervenir a través de un instrumento de política pública: la regulación económica. Este enfoque, que surgió inicialmente en Estados Unidos y luego se extendió a todos los países el mundo, sigue los lineamientos de la teoría del bienestar en el marco de los pilares del keynesianismo, y es conocido en el mundo académico como enfoque normativo, teoría del interés general o teoría tradicional de la regulación.

Posteriormente, hacia los años setenta del siglo XX, se reduce la confianza en los resultados positivos del Estado regulador, y el modelo regulativo es fuertemente criticado y controvertido, debido a los desaciertos del gobierno al ejercer la regulación, sumados a los fallos del mercado. Este hecho genera un nuevo punto de vista que va a orientar la regulación económica en el marco de la competencia, denominado enfoque positivo de la regulación, elección pública, teoría del interés privado o escuela de public choice. Razones de carácter ideológico, jurídico y económico, provocaron el cambio del modelo del Estado intervencionista a un modelo de mercado o de competencia.

El objetivo básico del presente artículo es presentar de manera clara y sencilla los principales presupuestos de partida, criterios y enfoques de la regulación económica, tanto explicativos como descriptivos, productos de la investigación terminada en el tema de regulación económica.

El artículo está estructurado en cinco partes. La primera contiene los antecedentes de la regulación económica; la segunda hace una crítica a la teoría tradicional de la regulación económica; la tercera está dedicada a la regulación económica: una aproximación al marco teórico y conceptual; la cuarta se centra en la eficiencia de la regulación, y en la quinta se presentan las conclusiones.

\section{Antecedentes de la regulación económica}

La intervención o no del Estado en la economía ha sido objeto de múltiples controversias y críticas a lo largo del tiempo. Se puede afirmar que en la Antigüedad

\footnotetext{
Situación en la cual la economía de mercado es ineficiente. Cuando ocurre un fallo del mercado, se produce demasiado de unas cosas y muy poco de otras.
} 
se dio alguna forma de intervención, igualmente en Grecia a través de los códigos, en el feudalismo, en el pensamiento mercantilista, en la doctrina clásica y neoclásica, posteriormente en el Estado intervencionista en el contexto de la teoría del bienestar, hasta los albores de la modernidad.

En la baja Mesopotamia, Hammurabi² (1760 a.C.) promulgó una compilación de leyes para que se cumplieran entre sus súbditos, conocida como Código de Hammurabi, para controlar los precios del ganado y la agricultura. Su fin era unificar todos los códigos del imperio babilónico. En Grecia, la crematística (del griego Khrema), el arte de hacer riqueza a través del comercio, atribuida a Tales de Mileto, estuvo relacionada con actividades económicas por parte del Estado en su proceso de relaciones con la comunidad. El manejo privado y colectivo a través de códigos jurídicos en la sociedad romana, donde se regulaba toda la actividad pública y privada, constituyó un sistema legal que prevaleció por mucho tiempo. En el Estado feudal como modo de organización política ya burocratizada, los individuos ejercían las funciones directivas de la sociedad, económicas, jurídicoadministrativas y militares. Progresivamente el Estado va ejerciendo el control y adquiriendo supremacía sobre la totalidad del territorio y en las relaciones sociales, económicas y políticas, y se va consolidando la construcción del Estado-nación.

El mercantilismo, que conjugó un conjunto de ideas políticas, floreció durante dos siglos y medio (1500-1750). En términos de Montchrestien (1999, p. 456), el papel del Estado mercantilista fue intervencionista, las funciones asignadas al Estado fueron: velar por el pleno empleo, dado que el paro es un desperdicio de recursos e implica un déficit de riqueza, concentrar su máxima atención en la fuerza laboral y mantener en orden sus aptitudes (Grampp, 1989, p. 156), otra función fue procurar la formación, desarrollo y enseñanza a las personas, el Estado debía ser responsable de la educación de los huérfanos, intervenir en la industria protegiendo las invenciones, creó monopolios gracias a los privilegios que concedía, en el comercio exterior debía proteger los bienes que produjera o pudiera producir la nación, defendía la libertad del comercio en cuanto a la producción nacional, otra función fue proteger la colonización porque ésta permitía absorber los excedentes de población, aumentaba la demanda y daba acceso a nuevas fuentes de materias primas.

Contrario al mercantilismo, que pregonaba la intervención del Estado en las funciones económicas, la escuela clásica, liderada por Adam Smith, pregonó la no intervención del Estado en la economía. Smith (1989, p. 256) centró su análisis en las funciones

\footnotetext{
2 Rey de Babilonia (1790-1750? a.C.). El código unificaba todos los códigos existentes en las ciudades del imperio babilónico. Pretendía establecer leyes aplicables a todos los casos, para impedir que cada uno tomara la justicia por su mano, pues sin ley escrita que los jueces tuvieran que aplicar obligatoriamente, era fácil que cada uno actuara como más le conviniera.
} 
del Estado y el modus operandi de los gobernantes; observó que estos procuraban sus propios intereses a expensas del interés público y consideró el orden económico como un orden natural, con racionalidad en sí mismo, que no debía estar mediatizado por ideas morales. Su tesis sobre la mano invisible consiste en que todo individuo se esfuerza por emplear su capital de tal modo que el valor de sus productos sea maximizado; por regla general, no se propone el interés general, e ignora además en qué medida lo logra. No se preocupa sino por su propia seguridad, de su propia ganancia o lucro y al actuar así, es conducido por una mano invisible para el logro de un objetivo que él no se había propuesto. Al perseguir su interés particular, sirve a menudo al interés social con mayor eficacia que en los casos en que tiene realmente la intención de promoverlo (Smith, 1989, p. 259).

Los mercados se autorregulan por un orden natural o leyes naturales a través de la mano invisible. Para Smith, el éxito en los negocios conduce al bienestar general, porque sus productos o servicios satisfacen a los ciudadanos compradores, lo cual implica que el mejor balance social es el balance económico, pero siempre con libertad e información para no perturbar la mano invisible ((Smith, 1989, p. 305). La no intervención del Estado en la economía prevaleció por más de siglo y medio.

A finales del siglo XIX surgió la escuela neoclásica, cuyos postulados marcaron un hito importante hasta la gran depresión económica mundial. Esta teoría se derivó de los postulados de las escuelas luciana, austriaca e inglesa. Sus máximos representantes fueron León Walras, Vilfredo Pareto, Carl Menger y Marshall (Walras, 2003, p. 125). Estas escuelas coincidieron en que el comportamiento económico surge del comportamiento agregado de los individuos que son racionales y tratan de maximizar su utilidad mediante acciones basadas en información completa (Schumpeter, 1982, p, 28).

El uso de las matemáticas fue relevante para interpretar y explicar el comportamiento de los mercados a través de la microeconomía. Esta explicó la aplicación de la oferta y la demanda y la conducta del consumidor, el análisis geométrico del equilibrio del consumidor, la producción y organización de la empresa mediante los productos marginales, la estructura y conducta de los mercados perfectamente competitivos, el análisis económico de los costes, el análisis económico del riesgo y la incertidumbre, entre otros, basados en la conducta de los individuos en el marco del enfoque marginalista.

Esta vertiente de pensamiento económico no supone las imperfecciones o fallos del mercado (Stiglitz, 2002, p.382), pregona la no intervención del Estado en la economía. La tesis central de los neoclásicos radica en que el mercado se autorregula por la interacción de la oferta y la demanda, y en que las condiciones de competencia, precios y equilibrio garantizan la asignación óptima de los recursos. 
Estos supuestos, acompañados de la ley de $\mathrm{Say}^{3}$, florecieron hasta la crisis del veintinueve del siglo XX, en la cual se pusieron en duda los postulados de la teoría neoclásica, dado que en la realidad el desenvolvimiento de los mercados ha mostrado que estos no funcionan en competencia perfecta, por el contrario, lo que existe son imperfecciones o fallos del mercado (asimetrías de información, formas de organización del mercado como monopolios, bienes públicos y externalidades), reflejados en un desorden económico. Estos desequilibrios desencadenaron la crisis económica mundial de finales de la segunda década del siglo XX. A medida que esta crisis sin precedentes se volvía más severa y ante la incapacidad del mercado de corregir los desequilibrios que generaba los fallos del mercado, el modelo no intervencionista iba moldeando la necesidad de intervención del Estado en la economía a través de un instrumento de política pública: la regulación económica.

Sin embargo, hay que aclarar que en 1887 hubo un intento de regulación. En Norteamérica se dieron los primeros intentos de regulación con la creación de la Comisión de Comercio Interestatal ICC, para regular precios, rutas y calidad del servicio de la red ferroviaria estatal, y se extendió a las líneas de transporte de carga, personas, transporte fluvial y oleoductos (Parkin, 2009, p. 327). El control fue gendarme y el primer conato de intervención del Estado en la economía fracasó, lo que hizo que permaneciera estática por más de cuatro décadas.

La intervención inicialmente surgió en Estados Unidos y luego se generalizó a los demás países del mundo, con el fin de lograr la confianza perdida por el desorden económico que había dejado el modelo no intervencionista. En este punto, el uso del derecho se transformó en derecho regulativo a través del establecimiento de normas jurídicas para controlar el comportamiento de los mercados.

El presidente norteamericano Franklin Delano Roosevelt, apoyado en los pilares del keynesianismo y principios de la teoría del bienestar, orientó sus políticas públicas en un ambiente macroeconómico totalmente contrario al modelo de "laissez faire" . La desolación económica de la gran depresión condujo al nuevo acuerdo (New Deal), sumado a las actitudes políticas que persisten en la actualidad; políticas agregadas, sectoriales y financieras, que pregonaban el interés general sobre el interés particular, conocido en el mundo académico como teoría tradicional de la regulación.

El derecho regulativo, en el marco de la teoría tradicional de la regulación, floreció hasta entrados los años setenta del siglo XX. El modelo regulativo no generaba

\footnotetext{
Toda oferta crea su propia demanda.

4 Expresión francesa, en la cual prevalece la necesidad de una acción libre, como principio decisivo para el bienestar de la comunidad sin la intervención del Estado ni ninguna otra actividad. Esto es, el funcionamiento de la economía debe dejarse al libre juego de la oferta y la demanda.
} 
confianza, pues, en la realidad, el objetivo propuesto orientado al interés general se sesgaba hacia el interés particular, y los problemas fueron mayores que los que se pretendieron resolver, porque además de los fallos del mercado, prevalecían los fallos del gobierno al ejercer la regulación.

El núcleo de las fuertes críticas se sustentó en que a través de la regulación se buscaba el interés privado o particular, explicado por el homo-economicus ${ }^{5}$ y el individualismo metodológico ${ }^{6}$, propios del comportamiento humano al buscar maximizar la riqueza (Pinzón, 2010, p.114). El anterior postulado se convirtió en la génesis del enfoque positivo, elección pública o public choice, que propone un modelo regulativo a través de la competencia o economía de mercado y, por ende, la desregulación, lo cual implica un Estado no intervencionista.

La regulación tradicional se desarrolla en torno al mercado político, que se convierte en protagonista y opera bajo reglas definidas, hace elecciones entre las opciones posibles de manera tal que maximiza su riqueza (Buchanan \& Brennan, 1985, p. 14). La regulación en el marco del mercado político derivó en lo que se conoce hoy día como teoría de la captura del regulador, en la que el regulador, a través de lobby, soborno o financiación a campañas políticas, permite que las normas sean diseñadas de manera tal que favorezcan a los regulados (Stigler, p. 256).

Para delinear los antecedentes de la regulación económica, se ha señalado una aproximación del papel del Estado en la intervención, la aplicación del derecho regulativo en un marco normativo. Posteriormente, el nuevo enfoque analiza que el objetivo regulativo fue totalmente contrario al objetivo propuesto, y propone, entonces, la eficiencia económica a través de la competencia o economía de mercado, tratando de alejar el comportamiento humano guiado en proporción significativa a procurar su propio lucro y aumento de rentas a través de posiciones privilegiadas en el gobierno y el poder económico.

\section{Crítica a la teoría tradicional de la regulación económica}

La edad de oro del capitalismo (1945-1973) se caracterizó por la expansión de la economía mundial, el aumento del producto interno bruto (PIB) en los principales países industrializados, salarios al ritmo de la productividad, altos índices de empleo y prestaciones sociales a cargo del Estado. El florecimiento del capitalismo empieza a declinar a partir del inicio de la década del setenta del siglo XX, como consecuencia del aumento del costo del capital por unidad de producto, inconvertibilidad del dólar y aumento del precio del petróleo. Hasta entonces, prevalecía la teoría del

El individuo busca maximizar su riqueza a través de un comportamiento oportunista.

$6 \quad$ Situación en la que prevalece el interés particular sobre el colectivo. 
bienestar o teoría tradicional de la regulación, en la cual la única justificación para la intervención del Estado en la economía eran los fallos del mercado. Los principales representantes de esta vertiente fueron Marshall y Pigou (a este último se le atribuye el concepto de fallos del mercado y el origen de la teoría del bienestar).

Hacia los años setenta, un nuevo enfoque de la regulación empieza a gestarse a la luz del floreciente análisis económico del derecho, en la escuela de Chicago norteamericana, promovido por autores que realizan aportes al nuevo enfoque regulativo desde la visión positiva, elección pública o public choice. La nueva vertiente sostiene que el Estado no es precisamente un Estado benevolente ni benefactor y además de los fallos del mercado, se adicionan los fallos del gobierno al ejercer la regulación, prevalece el poder económico y el poder político, aspectos claves e importantes, que no se habían tenido en cuenta en la teoría tradicional.

\section{Regulación económica: una aproximación al marco conceptual y teórico}

Se deben tener en cuenta dos visiones para definir el concepto de regulación. Primero, la teoría normativa, interés público o tradicional de la regulación, que incorpora los fallos del mercado, centra su justificación para corregir dichos fallos del mercado a través de la actividad reguladora, asociada a la teoría del bienestar social o interés público. Segundo, la visión positiva de la nueva teoría de la regulación económica, asociada al enfoque del interés privado, que, además de los fallos del mercado, incorpora los fallos del Estado al ejercer la actividad regulatoria.

\subsection{Teoría de interés público}

La regulación económica desde el enfoque del interés público, teoría normativa o economía del bienestar, conocida en el mundo académico como teoría tradicional de regulación, gira en torno a los pilares del keynesianismo. Consiste en una limitación impuesta por el sector público para restringir las elecciones de los agentes económicos; está orientada al interés social; considera que quienes ejercen el poder ofrecen regulación que logra eficiencia orientada al interés público; supone un Estado omnisciente, benevolente y benefactor. En términos de Parkin (2009, p. 327), en esta vertiente de pensamiento las normas protegen el control de precios a través de leyes antimonopólicas para garantizar que la producción aumente y los precios disminuyan.

Un regulador público ejerce control de precios sobre la actividad económica privada, vigila la tasa de rendimiento, eficacia marginal del capital o tasa de retorno ${ }^{7}$, establece

\footnotetext{
Conocida también como eficacia marginal del capital, consiste en la ganancia neta que le queda al inversionista una vez ha descontado la tasa de interés.
} 
tarifas multiprecio ${ }^{8}$, garantiza que la empresa cubra sus costos totales de producción y genere una ganancia racional. El propósito de la regulación fue orientar a la empresa a comportarse de manera eficiente y a la imposición de barreras a la entrada, y por eso los monopolios fueron regulados mediante leyes antimonopolio, empresas de economías de escala y monopolios naturales, siempre bajo el supuesto del interés general.

En general, a la luz de este enfoque, se puede considerar que la regulación consiste en el conjunto de normas administradas por el Estado, cuyo objetivo es la eficiencia económica de los mercados, a fin de favorecer a los consumidores y productores a través de la fijación de precios y cantidades, y de la determinación de condiciones a la entrada de nuevas empresas. Para Viscusi y Harrington (1995, p.52), quienes tienen otra interpretación del concepto, la regulación económica consiste en una limitación impuesta por el sector público, para restringir las elecciones de los agentes económicos; supone la existencia de un Estado benevolente, que impedirá que los agentes con poder de mercado, afecten el bienestar de la sociedad con actividades que lleven a la obtención de beneficios privados.

La intervención del Estado en la economía a través del derecho regulativo generó diversos debates, el punto de inflexión se presentó a partir de los años setenta y se extendió a escenarios académicos, gubernamentales, administrativos, nacionales e internacionales. La polémica responde a razones ideológicas, económicas y jurídicas (Ariño, 2003, p, 685). Desde el punto de vista ideológico, se pregona por políticas de liberalización que confían más en el mercado que en la normatividad regulatoria; la concepción jurídica estuvo orientada a la experiencia de las controvertidas directivas europeas y norteamericanas frente a la regulación del sector energético; y el enfoque económico busca la eficiencia a través de la competencia, con base en la planificación empresarial, la descentralización y en la formación de precios.

El argumento es el fracaso del modelo tradicional, que se reflejaba en la deuda que condujo a crisis en los años setenta a países de América Latina, África y el oriente de Europa, lo que confirmaba la desconfianza del modelo regulativo pero, más aún, de los reguladores públicos que ejercían el rol de reguladores pensando siempre en el interés personal y alejándose del interés público.

\subsection{Teoría del interés privado o elección pública}

La génesis del interés privado o la elección pública se remonta a las concepciones de Thomas Hobbes y Benedicto Spinoza y James Madison y Alexis de Tocqueville,

Depende si el uso se hace en horas valle u horas pico. 
en el siglo XVIII y XIX, desde la filosofía política y la ciencia política respectivamente. Hobbes realiza aportes acerca del Estado y aleja el supuesto de romanticismo y armonía entre las personas. Por su parte, Spinoza explica la relación entre la fuerza y el poder desde la compleja concepción de la filosofía política, ontológica, antropológica y ética de la dimensión política, "el poder permite comprender la concepción del individuo y al mismo tiempo permite acceder al sentido del Estado como directa consecuencia de la configuración de los sujetos" (Echaverría, 1989, p. 10).

La concepción de Madison es básicamente política, para el autor el peligro proviene de la apasionada toma de decisiones del gobierno. El problema que ha impedido resolver la tiranía del gobierno es la ignorancia persistente de cada persona combinada con cada rama de la función del gobierno. La tiranía la ejerce la mayoría a través de dos instrumentos: el gobierno y la ley (Kernell, 2003, p. 349). Por su parte, la concepción de Tocqueville se centra en la democracia en la que se incuba la burocracia y el poder; en la sociedad lo que separa a las personas es el poder, dado que este es más eficaz que cualquier otro sistema político, luego, la democracia y el poder aumentan la propiedad privada y pública.

Otro importante antecedente del nuevo enfoque de pensamiento económico, fue el análisis de Arthur Bently acerca del comportamiento de los individuos cuando tienen el poder de gobernar:

Gobernar es un proceso del que son protagonistas los grupos de interés, un grupo de interés o de presión es una porción de la sociedad caracterizado por tener un interés común y pertenecer a uno de tales grupos no impide formar parte del otro ya que una persona no tiene uno sino múltiples intereses, los instintos, sentimientos innatos, facultades intelectuales y aún las ideas e ideales de las personas resultan poco eficaces para explicar su comportamiento como funcionario público (Bently, 1908).

El autor tiene un razonamiento realista, percibe la interacción entre grupos de interés en constante actividad presionando los unos a los otros, cooperando, compitiendo, formando alianzas ofensivas y defensivas; son grupos políticamente poderosos, que dominan, delinean y configuran el estado existente de la sociedad (Zablotsky, 1996, 86).

La siguiente paráfrasis es la continuación de las ideas de Bently retomadas por Buchanan y permiten acercarse a la concepción del interés privado o enfoque positivo: 
Cuando en la política se modelan las personas como poseyendo intereses propios tal y como sucede en otros aspectos del comportamiento, el desafío constitucional, se convierte en el diseño y construcción de instituciones básicas o reglas que limiten al máximo el ejercicio de tales intereses (Buchanan \& Tullock, 1962, p. 14).

Obsérvese que su contenido vislumbra la inclusión del egoísmo, comportamiento oportunista y el interés particular sobre el interés colectivo, esto es los principios del homo economicus e individualismo metodológico. El primero lleva implícito el principio de racionalidad completa, que consiste en un supuesto motivacional del interés propio, definido en términos materialistas y unidos normalmente a la racionalidad completa (Toboso, 1991, p. 6). El segundo se relaciona con la reduccionista exigencia de que todas las teorías de las ciencias sociales han de ser reducibles a teorías sobre la acción humana individual y todos los fenómenos sociales, colectivos e instituciones deben ser explicados con base en las acciones humanas (Rutherford, 1994, p. 24).

Con el anterior preámbulo, desde la visión de la teoría del interés privado, enfoque positivo, elección pública o public choice ${ }^{9}$, surge a partir de los años setenta del siglo $\mathrm{XX}$, con un nuevo análisis a la regulación y fuertes críticas a la teoría tradicional. El nuevo enfoque se delineó en el marco de cuestionamientos: ¿el mecanismo para corregir los fallos del mercado no generan daños peores?, ¿por qué falla el gobierno en su rol de regulador?, ¿cuáles son las fallas? La aproximación a estos cuestionamientos se encuentra en la distribución de la riqueza, y el Estado es un escenario y mecanismo perfecto utilizado por agentes racionales con dicho fin; por lo tanto es en la redistribución en la cual se encuentra la esencia misma del comportamiento del gobierno, ¿por qué? la respuesta es contundente: búsqueda de riqueza particular a través de la distribución y el poder.

El enfoque se orienta desde una perspectiva diferente a la teoría tradicional, supone una forma adaptativa y evolutiva de la regulación (Buchanan \& Brennan (1985, p. 27), incluye en su análisis la teoría económica del gobierno, la regulación de monopolios, individuos que persiguen intereses individuales, los grupos de presión, la sostenibilidad e inconsistencia de las decisiones y la captura del regulador ante los intereses particulares o personales. Los individuos se modelan como entes que persiguen sus propios intereses personales, en términos de posiciones netas de renta, mensurables, tanto predecibles como esperadas, bajo un esquema oportunista a través del intercambio político.

Escuela que se basa en aplicar los criterios de la decisión individual (la máxima de la preferencias individuales sujetas a determinadas restricciones) a las decisiones de organismos e instituciones públicas. Este enfoque se basa en las ideas de Buchanan, seguidas por Richar Posner (2000), George Stigler (1971a, 1971b) Peltzman (1998) y Becker (1984), entre otros. 
La Elección Pública es una diferente manera de mirar los procesos políticos, diferente de aquella otra forma de mirar esos mismos procesos que surge de la perspectiva $o$ enfoque del poder... existen en todo caso, grandes contribuciones a hacer mediante la extensión de ambas expectativas, a lo largo de todo el espectro de instituciones. En este sentido, utilizar la perspectiva de la Elección Pública para el análisis de los procesos políticos, resulta algo análogo al utilizar la perspectiva del poder, para el estudio de los mercados; la política constituye una estructura de intercambio complejo entre individuos, una estructura mediante la cual, los individuos buscan asegurar colectivamente aquellos objetivos propios previamente definidos, que no puedan ser realizados a través de los intercambios simples de mercado. (Buchanan, 1993).

La hipótesis sobre la que se sustenta la elección pública o public choice, acota que las normas a largo plazo y la regulación reflejan un contrato incompleto que evoluciona en función de los intereses de los grupos implicados (Buchanan \& Tullock, 1980, p. 52). Por otra parte, en la economía política constitucional se analiza la forma de tomar decisiones en el marco de unas reglas establecidas, las propias reglas y la posibilidad de medir su eficacia (Buchanan \& Brennan, 1985, p. 41), en otras palabras, las constituciones deben ser diseñadas de forma que los políticos que procuren los intereses públicos puedan sobrevivir, por consiguiente, el papel de las reglas es fundamental, "necesitamos reglas en la sociedad porque sin ellas la vida sería solitaria, pobre, sucia, brutal y corta" (Buchanan \& Brennan,1985, p. 43). Obsérvese la concordancia con Hobbes:

Solamente el anarquista romántico piensa que hay una armonía natural entre las personas que elimina todo conflicto en ausencia de reglas. Necesitamos las reglas para vivir juntos, por la simple razón de que sin ellas seguramente nos pelearíamos, pues lo que un individuo deseare seria apetecido, casi que con certeza, por, cualquier otro. (Hobbes, 1994)

Las anteriores reflexiones definen los espacios privados dentro de los cuales cada uno puede llevar a cabo sus propias actividades. Esta nueva vía de la elección pública analiza, como se ha mencionado, el mercado político en el que el gobierno es una organización compleja compuesta por individuos donde cada cual busca su interés particular y la política gubernamental es el resultado de elecciones que realizan estas personas donde se integran votantes, empresas, políticos y burócratas (Parkin, 2009, p. 325).

La teoría positiva es desarrollada y ampliamente analizada por destacados autores como Richard Posner (1969), Gary Becker 1984), Sam Peltzman (1976), y George Stigler (1971), entre otros, sus valiosos aportes los realizan siguiendo el hilo conductor de Buchanan y Tullok. 
La visión de Posner ${ }^{10}$, se centró en la existencia de monopolio natural ${ }^{11}$, así es inevitable la existencia de monopolios; para evitar la fijación de precios monopolistas el Estado debe regular haciendo uso de las leyes antimonopolio. El monopolio natural plantea tres problemas que justifica la regulación pública: el precio monopólico, aliento a la entrada ineficiente y dificultad para elaborar una estructura de precios eficiente. Respecto al precio de monopolio, la empresa que abastece un mercado de monopolio natural, tiene el mismo incentivo que cualquier otra para maximizar su beneficio restringiendo su producción y tiene mayor probabilidad porque no tiene que incurrir en costos legales y administrativos de la colusión o adquisición corporativa para hacerlo. En cuanto al aliento a la entrada ineficiente, el monopolista vende una cantidad determinada a un determinado precio, el cual se fijará cuando el costo marginal sea igual al ingreso marginal. Un nuevo participante viendo que puede abastecer a una parte del mercado a un costo medio menor que el precio de mercado, tiene incentivo para entrar, pero cuando lo hace la empresa existente deberá reducir el precio o la producción. Si decide reducir la producción, el costo medio de la producción será mayor de lo necesario (Posner, 2000, p. 238).

La dificultad para elaborar una estructura de precios eficiente consiste en que si la última unidad producida cuesta menos que el costo medio de todas las unidades, y si en estas circunstancias la empresa vendiera toda su producción al costo marginal, su ingreso total sería menor que el costo total, y respecto a la regulación de entrada y la estructura de precios, la regulación de entrada descansa en el nivel global de precios del monopolista regulado, es frecuentemente ineficaz o tiene propósitos diferentes (Posner, 2000, p. 241).

El autor dedica gran parte de su estudio al tema de la regulación, hace un profundo análisis en tres aspectos claves: impacto del monopolio natural sobre la sociedad en ausencia de regulación, proceso regulatorio y sus costos y beneficios sociales, posibilidades de reformas constructivas y alternativas de regulación. Indica que el monopolio natural se regula en aspectos tales como: precios, ingreso al sector y estructura de precios; y se justifica por varios argumentos: precios y utilidades monopolísticas, ineficiencias internas del monopolista, incapacidad de optimizar el

10 Economista y magistrado desde 1981 de la Corte Suprema de los EstadosUnidos. Ha investigado sobre la aplicación de la teoría económica a diversos campos jurídicos como la legislación antimonopolista, la regulación de los contratos mercantiles y el procedimiento judicial. Propuso y defendió la idea de que la ley puede ser explicada mejor bajo el supuesto de que los jueces tratan de promover la eficiencia económica y la maximización de la riqueza como objetivo de la política legal y social. Se convirtió así en uno de los más destacados líderes de la corriente del Análisis económico del derecho (Law and Economics).

11 situación en la que los costos fijos son muy grandes en relación con la demanda, si tales costos pueden repartirse entre toda la producción del mercado, una sola empresa que provea esa producción podría tener un costo medio de producción menor que dos o más empresas igualmente eficientes. 
cambio tecnológico, no prestación de servicios, bienes y servicios inferiores, insatisfacción de las preferencias de los consumidores. Para el autor, la mecánica de la regulación consiste en la determinación de los ingresos de la empresa regulada (Posner, 1969, p. 322).

Becker enfocó el interés privado en la regulación, en la que prevalece la presión sobre el regulador a través de los grupos de interés, pues cada grupo de interés intenta maximizar el beneficio para cada miembro del grupo (Becker, 2006, p, 12); entonces las políticas públicas que se expidan pueden distorsionar los objetivos económicos de los agentes, de manera que la presión está en función del tamaño del grupo, si este es grande la presión será mayor. El autor analiza la regulación económica desde la perspectiva de la demanda de regulación de los grupos de interés para buscar mayores beneficios.

Otro valioso aporte en el marco de la elección pública es la oferta regulatoria desde el mercado político, donde votantes, empresas, burócratas y políticos hacen acuerdos que más les acerquen a sus objetivos particulares. Los acuerdos entre estos grupos de interés se denominan equilibrio político (Peltzman, 1998, p. 26). Pero, ¿todos los grupos estarán de acuerdo? A este cuestionamiento algunos políticos y sus partidarios utilizan estrategias a través de mecanismos como presión, lobby, inyectan dinero a campañas políticas para tratar de cambiar a su favor las leyes. De lo anterior se ratifica el postulado de Buchanan en el sentido que la regulación se asimila a un contrato incompleto que evoluciona en función del interés de los grupos implicados en un determinado mercado.

La teoría de la captura del regulador fue un importante análisis en el contexto del nuevo enfoque desarrollada por Stigler, quien sacó a la luz pública los planteamientos de los grupos de interés, que por varias décadas habían permanecido ocultos, analizó el funcionamiento de los mercados, siguiendo los lineamientos de Bently. El autor partió de los aspectos básicos del funcionamiento de los mercados en la economía del bienestar o del interés general, que se apoyaban en los presupuestos de competencia perfecta.

Los mercados completos e información perfecta, fue el aspecto que llamó la atención y en el cual centró su análisis; el punto clave fue en la naturaleza de la competencia perfecta. Consideró las tres condiciones necesarias para su existencia. Primero, cada unidad económica (empresa o familia), debe ser tan pequeña, comparada con el mercado, que no ejerza una influencia perceptible sobre los precios de los artículos que se compran y venden. Segundo, no deben existir restricciones sobre los precios y la movilidad. Tercero, todas las unidades económicas deben poseer información adecuada (Stigler, p. 254). 
El siguiente párrafo examina la inconformidad de Stigler frente al supuesto de competencia perfecta, la duda del Estado benefactor y, por consiguiente, el sesgo hacia grupos de interés privados. En términos de Stigler, las dos primeras condiciones expuestas en el párrafo anterior son obvias, mientras que la tercera es más complicada. Explica cómo la competencia no es perfecta, si una empresa independiente puede producir una cantidad de un artículo tal, que un aumento de su actividad pueda disminuir en forma perceptible el precio. La empresa controla el precio al regular su producción, y es el control del precio una de las características del monopolio. Si se aplican restricciones a los precios o a la movilidad de los factores de la producción en cualquier terreno, se puede afirmar que se restringe el mercado competitivo, lo que significa que compradores y vendedores no tienen influencia en el precio, por medio de sus compras o ventas, es decir, que la elasticidad de la oferta ${ }^{12}$ frente a cualquier comprador es infinita (Stigler,1971b, p. 167), y la elasticidad de la demanda ${ }^{13}$ respecto a cualquier vendedor, es también infinita; luego la competencia y las restricciones son de tipo legal. Si el consumidor, en términos de Stigler (1971b, p. 168) desconoce el precio de mercado, compra a un precio mayor cuando podría hacerlo con mayor economía y existen varios precios para un mismo artículo. Por ejemplo, si los hombres de empresas desconocen los costos y los precios, aumentarían la producción aumentando pérdidas y otras veces, disminuirían los beneficios; por lo cual, los miembros de un sistema económico deben conocer el mecanismo para que el sistema funcione bien.

Ahora bien, la captura del regulador opera solo en función de los grupos de interés de los productores. Se basa en que el costo de organización política es alto y el proceso político proporciona regulaciones que aumentan el excedente de los grupos pequeños que compiten por influencia legislativa (Stigler, p. 136). De lo anterior se puede interpretar que en el frecuente contacto entre regulados y reguladores, los primeros pueden ejercen mecanismos de presión sobre el regulador para que las regulaciones sean diseñadas de manera tal que favorezca los grupos de interés. Pero surge una interrogante ¿cómo determinar si hay captura del regulador? La respuesta está en función de la tasa interna de retorno de inversión, esto es, si el productor genera jugosas ganancias superiores a las del resto de la economía, se puede afirmar que hay captura del regulador.

Los anteriores planteamientos dejan ver que no existe una definición única y de pizarrón de la regulación económica, su concepto está en función de la óptica desde donde se quiera interpretar y analizar. El siguiente segmento se aproxima a una explicación del objetivo de la regulación: la eficiencia económica.

12 Su significado económico consiste en el cambio porcentual de la cantidad ofrecida frente a un cambio porcentual en el precio del bien producido.

13 Su significado económico consiste en el cambio porcentual en la cantidad demandada frente a un cambio porcentual en el precio. 


\section{Eficiencia económica de la regulación}

La eficiencia económica en la regulación tiene dos componentes: la eficiencia asignativa (mayor excedente al consumidor) y la eficiencia productiva (mayor excedente al productor), como respuesta a las economías de escala ${ }^{14}$, al compensar la ausencia de presiones competitivas y prevenir la competencia excesiva que había llevado a guerras de precios y asegurar el acceso universal a los servicios públicos.

La concepción y fin último de la regulación es garantizar el criterio de eficiencia económica. El objetivo de la eficiencia regulatoria consiste en que los beneficios no sean solamente para los empresarios, sino que a través de esta, se cumplan los postulados que justifican la regulación para la competencia: buscar mayor eficiencia en el sentido de ofrecer más ampliación de cobertura y mejor servicio a menor costo (redistribución del ingreso).

\subsection{Eficiencia productiva}

Para introducir el concepto de eficiencia productiva, es necesario considerar que los recursos son insumos o factores utilizados en la producción de bienes o servicios; estos recursos tienen una particularidad: la escasez. Este es el concepto y el problema básico de toda la ciencia económica, en torno al cual se desarrollan las actividades económicas, dado que los recursos productivos son siempre limitados y las necesidades de bienes y servicios para satisfacer las necesidades son ilimitadas, por lo tanto, la escasez es un problema que afecta a todas las personas, a todas las organizaciones, todas las empresas y a la sociedad en general.

La eficiencia es un concepto económico justificado por la escasez de recursos susceptible de empleo en usos alternativos. Cada empresa elige la combinación de insumos que le permite obtener una determinada cantidad de producción de bienes o servicios. El concepto de eficiencia productiva, consiste en la evaluación de cómo una empresa consigue la producción de esos bienes y servicios.

14 Empresas que incorporan en su proceso productivo tecnología de punta para disminuir los costos de producción. 


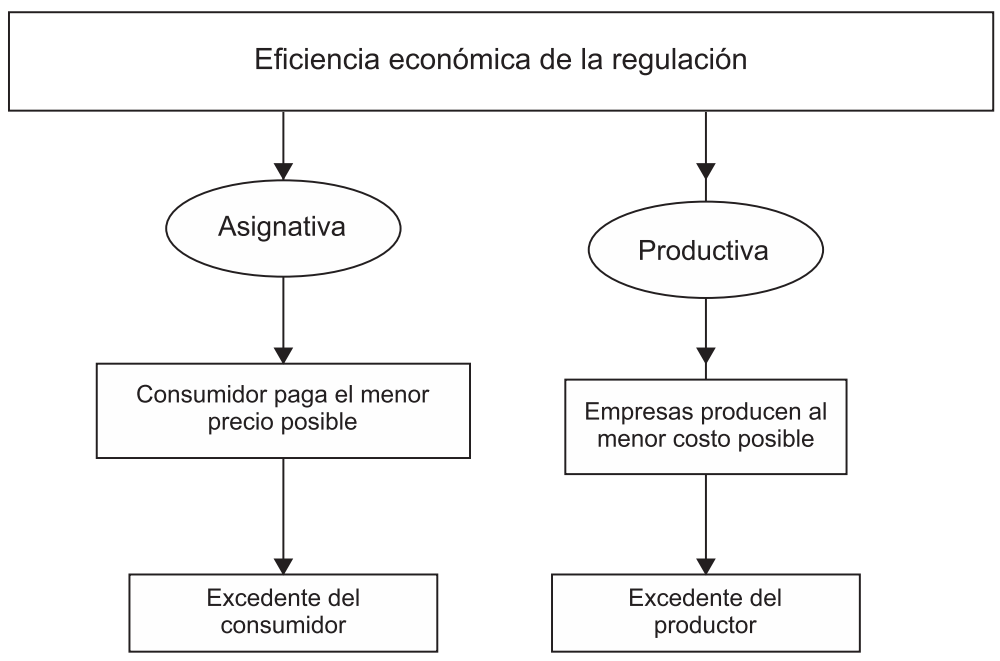

Figura 1. La eficiencia Económica de la regulación / Fuente: construcción propia a partir de la información consultada.

\subsection{Eficiencia asignativa}

La eficiencia asignativa tuvo su origen y se desarrolló ampliamente en la economía del bienestar de Vilfredo Pareto, consiste en que el regulador diseña un esquema de precios de manera tal que el consumidor pague el menor precio posible. Ahora bien ¿cuál es alcance de ésta?, ¿cuál es el impacto de la función de regulación y la protección al consumidor? Una aproximación a resolver las interrogantes sería en el sentido de comprender la regulación como un instrumento de política pública, que actúa en el escenario con alcance constitucional y legal y con un fuerte impacto en la protección al consumidor a nivel internacional (Stiglitz, 2002, p.82), por una parte evitando que el productor genere mayor ganancia como consecuencia de elevar el precio, lo cual se ve claramente reflejado en la disminución del ingreso del consumidor, dicha intervención ha permitido asegurar mayor ingreso a través de la protección al consumidor.

Estas cuestiones han dado lugar a plantear fórmulas concretas, la siguiente expresión: $\mathrm{W}(\mathrm{p})=\mathrm{E}(\mathrm{p})+£ \pi(\mathrm{p}) ; \mathrm{W}(\mathrm{p})$ (Lasheras, 1999, p, 37). La primera expresión de la derecha corresponde al excedente del consumidor; si $E^{\prime}(p)<0$ significa que la eficiencia asignativa está disminuyendo, desfavoreciendo al consumidor, (p) $<0$ significa que la eficiencia asignativa está disminuyendo, desfavoreciendo al consumidor, porque el mayor precio que este último paga, lo está recibiendo la empresa, y esta estará aumentando sus beneficios. La eficiencia asignativa pretende maximizar el bienestar social; es decir, fijar precios cercanos al costo de producción, con el fin de evitar tasas de retorno o rentas excesivas para las empresas. 


\section{Conclusiones}

Con base en los argumentos y consideraciones presentadas en este artículo, es posible afirmar que la intervención o no del Estado en la economía ha generado debates, controversias, análisis y diferentes interpretaciones a lo largo del tiempo. En los diferentes modos de producción prevaleció alguna forma de intervención a través de códigos y delegación de funciones jurídico -administrativas a los individuos en la sociedad. En el sistema mercantilista, que abogaba por el Estado intervencionista, la escuela clásica es tajante: el Estado no debe intervenir en la economía, los mercados se regulan de forma natural, el instrumento regulatorio es la mano invisible. En la escuela neoclásica, los mercados se autorregulan, el instrumento regulatorio son las fuerzas de las variables oferta y demanda.

El punto de inflexión que separa el Estado no intervencionista del Estado intervencionista, fueron los desequilibrios que generaban fallos del mercado, derivados del postulado de la teoría neoclásica, los mercados funcionan en competencia perfecta, lo cual había llevado a la economía a una crisis económica mundial sin precedentes. La realidad mostraba que lo que prevalecía eran las imperfecciones o fallos del mercado, y para corregir dichos fallos el Estado debía intervenir a través de un instrumento de política pública: la regulación económica.

El Estado intervencionista se inició en Norteamérica hacia 1887, pero fue gendarme y se opacó rápidamente. Reanudó su actividad en los primeros años de la década de los años treinta del siglo XX, siguió los pilares del keynesianismo en el marco de la teoría el bienestar. Su objetivo se orientó al interés general a través de las normas, de allí deriva su nombre: teoría normativa, del interés general o tradicional de la regulación. Teoría que floreció durante cuarenta años, esto es, durante la edad de oro del capitalismo.

A partir de los años setenta del siglo XX, surgen fuertes críticas y controversias al Estado regulatorio, los análisis e investigaciones concluían que generaba más problemas de los que pretendía resolver, porque a los fallos del mercado se sumaban los fallos del gobierno al ejercer la regulación.

Las razones de las críticas fueron de carácter ideológico, jurídico y económico, consideradas génesis del nuevo enfoque, que sostenía que las actividades regulatorias las ejercían individuos con poder económico y político que sesgaban el objetivo de la regulación del interés general hacia el interés particular o privado haciendo uso de diferentes mecanismos como lobby, soborno, financiación de campañas políticas, entre otros. El nuevo enfoque no estuvo de acuerdo con la teoría tradicional de la regulación, dado que en la realidad orientaba sus objetivos en función del comportamiento de los individuos buscadores de mayores rentas, a partir de los principios del homo-economicus y el individualismo metodológico. 
Este artículo ha permitido materializar la escisión de la regulación económica a partir de una aproximación a los antecedentes, al marco teórico y conceptual y a las dos grandes vertientes: la teoría normativa, tradicional o del interés general y la teoría positiva, del interés privado, elección pública o public choice. La primera pretende corregir los problemas de la economía mediante el derecho regulativo a través de normas, y la segunda se enfoca, por el contrario, en la desregularización utilizando como instrumento regulativo la competencia y economía de mercado.

En general, las políticas de finales del siglo XIX generaron desórdenes derivados de las leyes naturales, y a finales del XX las decisiones norteamericanas e inglesas ocasionaron caos financieros que hicieron dudar de las bondades de la competencia para la regulación de los mercados así las cosas se reconoce la importancia del intervencionismo propio de la teoría normativa a la luz de las ideas keynesianas.

En último término, me interesa dejar abiertos algunos cuestionamientos: ¿la regulación económica es una condición necesaria para la confianza de los mercados?, ¿quién controla al que controla?, el objetivo de estas interrogantes es abrir espacios analíticos, críticos y propositivos en torno al tema. Este no es un artículo definitivo, por el contrario abre espacios para análisis, interpretación y nuevas publicaciones.

\section{Referencias}

Ariño, G. (2003). Principios de derecho público económico. Modelo de Estado, gestión pública, regulación económica. ( $1^{\mathrm{a}}$ ed.). Bogotá: Universidad Externado de Colombia.

Becker, G. (2006). Public policies, pressure groups and dead weight of costs. Journal of Political Economy. London: The Institute for Fiscal Studies.

Bently, A. F. (1908). The process of government. A study of social pressures. Chicago: University of Chicago.

Buchanan, J. (1993). The public choice perspective. In Public choice theory. Vol 3. England: Aldershot.

Buchanan, J. \& Tullock, G. (1980). El cálculo del consenso: fundamentos lógicos de la democracia constitucional. Madrid: Espasa Calpe.

Buchanan, J. M. \& Brennan, G. (1985). La razón de las normas. Unión Editorial.

Echeverría, P. F. J. (1989). La filosofía política de Spinoza. Universidad de Valladolid, España.

Grampp, W. (1989). Arte, inversión y mecenazgo. Un análisis económico del mercado del arte. Barcelona: Ariel.

Hobbes, T. (1194). Leviatán. Vol. 1. México: Gernika.

Kernell, S. (2003). The theory and practice. California, USA: Stanford University Press. 
Lasheras, M. A. (1999). La regulación económica de los servicios públicos. Barcelona: Ariel.

Montchrestien de Antoine. (1999). El Traité de Economice Politique Genéve. Recuperado de htpp/www.persee.fr/.../hes_05702_2001.

Parkin, M. (2009). Economía. (8 ed.). M. A. Sánchez (trad.). Canadá: Parson Addison Wesley, University of Western Ontario.

Pinzón, M. A. (2010). Aproximaciones al análisis económico del derecho. Bogotá: Editorial Universidad Externado de Colombia.

Posner, R. (2000). Análisis económico del derecho. E. Suárez (trad.). México: Fondo de Cultura Económica.

Posner, R. A. (1969). Natural monopoly and its regulation. Washington D.C.: Cato Institute.

Rutherford, M. (1994). Institutions in economics. Cambridge: Cambridge University Press.

Peltzman, S. (1998). Toward a more general theory of regulation. Journal of Law and Economics of The University of Chicago.

Schumpeter, J. A. (1982). Historia del análisis económico. (2 ed.). Barcelona: Ariel.

Smith, A. (1986). The wealth of nations. Nueva York: Modern Library.

Stigler, G. (1971a). The theory of Economic Regulation. The Bell Journal of University Economics and Management of The University of Chicago.

Stigler, G. (1971b). La teoría de los precios. Madrid: Editorial Revista de Derecho Privado.

Stiglitz, J. (2002). La economía del sector público. Barcelona: Antoni Bosch.

Toboso, F. (1991). El papel del homo-economicus en la teoría positiva de la elección pública. Cuadernos de Economía, 19(55).

Viscusi, K, Vernon \& Harrington, J. (1996). Economics of regulation and antitrust. Cambridge: The MIT Press.

Walras, L. (2003). Estudios de economía social. En M. Vuotto (comp.). Economía social, precisiones conceptuales y algunas experiencias históricas. Buenos Aires: Altamira.

Zablotsky, E. (1996). La escuela de economía política de Chicago. Revista Ciencia Hoy, $6(32)$.

\section{Bibliografía recomendada}

Baldwin, R. \& Cace, M. (1999). Understanding regulation, Theory strategy and practice. Oxford University Press.

Segura, J. (2004). Competencia, disciplina de mercado, regulación en presencia de conflictos de intereses en las empresas. Madrid: Hacienda Pública Española, Instituto de Estudios Fiscales de Madrid.

Sharkey, W. (1982). The theory of natural monopoly. Cambridge: Cambridge University Press. 